\title{
Schreger pattern analysis of Mammuthus primigenius tusk: analytical approach and utility
}

\author{
MARTINA ÁBELOVÁ
}

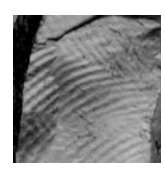

\begin{abstract}
Analyses of the characteristic structural Schreger pattern in the dentine of tusks of numerous fossil proboscidean Mammuthus primigenius (Blumenbach, 1799) from five Upper Palaeolithic (Gravettian) Moravian localities (35-25 cal. ka BP) [Předmostí, Pavlov, Dolní Věstonice, Milovice and Napajedla] and one Würmian Croatian locality Viljevacki cret (Donji Miholjac) reveal the microstructure within the dentine. Values of the Schreger angles, the qualitative appearance of the pattern, and the wavelengths in transverse and longitudinal sections of the tusks were determined showing that Schreger angles can reach around $25-40^{\circ}$ near the pulp cavity, begin to increase towards the tusk surface (cement-dentine junction - CDJ), and reach a maximum of around $125^{\circ}$. Wavelengths reach maximal values of around $2,175 \mu \mathrm{m}$ at low Schreger angles, towards the tusk surface becoming shorter and measuring around 1,100 $\mu \mathrm{m}$. The qualitative pattern appearance depends mainly on the Schreger angle with a so-called ' $V$ ' pattern occurring at low angles, that is between $25-70^{\circ}$. At a maximal angle value (approximately from $80^{\circ}$ to $125^{\circ}$ ) the so-called ' $\mathrm{C}$ ' pattern occurs near the tusk surface. An ' $\mathrm{X}$ ' pattern occurs with angle values around $70-80^{\circ}$ lying between ' $\mathrm{V}$ ' and ' $\mathrm{C}$ ' patterns. $\bullet$ Key words: Schreger pattern, Mammuthus primigenius, tusks, microscopic study, histology, vertebrate palaeontology.
\end{abstract}

ÁBELOVÁ, M. 2008. Schreger pattern analysis of Mammuthus primigenius tusk: analytical approach and utility. Bulletin of Geosciences 83(2), 225-232 (6 figures, 3 tables). Czech Geological Survey, Prague. ISSN 1214-1119. Manuscript received May 9, 2007; accepted in revised form March 4, 2008; issued June 30, 2008.

Martina Ábelová, Masaryk University, Faculty of Science, Institute of Geological Sciences, Kotlářská 2, 61137 Brno, Czech Republic; abelova.m@mail.muni.cz; State Geological Institute of Dionyz. Stur, Mlynská dolina 1, 81704 Bratislava 11, Slovak Republic; martina.abelova@geology.sk

Tusks in the Proboscidea, also known as ivory, are an extended, ever-growing pair of second incisive teeth. Despite its importance in human history and technology, ivory remains a material that is only poorly understood. Tusks keep growing throughout the lifetime of the animal by addition of dentinous incremental layers and corresponding build-up of the tusk volume. The pulp cavity is located at the proximal end of tusk and during the animal's life it contains blood vessels, nerves and lymphatic tissue. Tusk growth patterns vary depending on the sex, age and reproductive status of the individual (Fox 2000).

Proboscidean dentine is composed of a hierarchical system of growth layers, which are subdivided into first-order (annual), second-order (generally bi-weekly) and third-order (daily) physiological accumulation cycles (Halberg et al. 1965, Halberg 1969, Fisher 2001). When observing a tusk under the light microscope the criss-cross 3-D dentine pattern that is represented by three-dimensionally interlaced prismatic bundles, which is typical only of proboscideans, can be seen. The tusk cross section shows a pattern consisting of intersecting lines forming minute diamond-shaped parts, which are visible at the dentine surface even with naked eye (Saunders 1979). This pattern consists of two line sets starting at the tusk centre and coiling up towards its periphery. One set of lines is coiled sinistrally and the other dextrally so that they intersect each other, subdividing the area into rhombic-shaped domains (Fig. 1), which decrease in size towards the centre. Tobien (1978) described it as "guillochage" whereas the same is specified as the "engine turnings" or "Schreger Pattern", according to Espinoza \& Mann (1991). The pattern was first described by and then named after Bernard Schreger (1800); this pattern is chessboard-like rather than a system of incremental lines. The Schreger bands result from corrugation of the dentinal tubules. This Schreger pattern is highly important in the identification of ivory genuineness (Saunders 1979) and is so singularly characteristic of proboscidean tusk dentine that Richard Owen (1840-1845) defined 'ivory' by its presence. Although the pattern is also present in proboscidean molar teeth dentine, it is best developed in tusks. However, some overlaps exist in the measured Schreger angle values, which is the angle of intersection between dextral and sinistral lines. Many Schreger lines are not continuous all over the beam-like thickness of the tusk. The total number of lines also varies - frequently the number of lines de- 


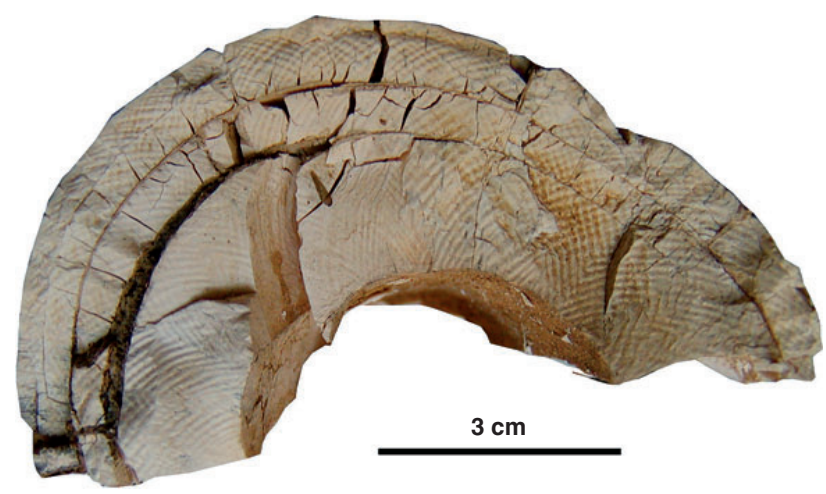

Figure 1. Schreger lines and qualitative pattern type 'C' and ' $V$ ' shown in cross section of a Mammuthus primigenius tusk from Předmostí. The Schreger angle reaches about $115^{\circ}-120^{\circ}$ near the tusk surface (at ' $\mathrm{C}$ ' pattern) and about $60^{\circ}$ near the pulp cavity (at ' $\mathrm{V}$ ' pattern).

creases towards the tusk axis - this phenomenon can be related to the variable accumulation of odontoblasts and variation in the density of dentinal tubules depending on the variable distance from the tusk axis (Saunders 1979, Raubenheimer et al. 1998).

Espinoza \& Mann (1993), Fisher et al. (1998), Palombo \& Villa (2001), Trapani \& Fisher (2003), and Lambert (2005) used Schreger pattern features, specifically Schreger angle values, to distinguish tusk dentin of various proboscidean species. Other workers interested in conservation and forensic questions have used trace element analysis (Prozesky et al. 1995, Shimoyama et al. 1998) and non-destructive Raman spectroscopy (Edwards et al. 1997, Shimoyama et al. 1997, Brody et al. 2001) to distinguish tusks and artefacts of Loxodonta, Elephas, and Mammuthus from each other. Kautenburger et al. (2004) used multi-element analysis by X-ray fluorescence for identification of ivory from various origins. Recently, Herrera (1999), Abramova et al. (2001), Khlopatchev (2001), Scheer (2001), Vasilev (2001), and Gelvin-Reymiller et al. (2006) studied ivory from the archaeological point of view.

In this study useful methods for the analysis of Schreger patterns are presented and discussed using Mammuthus primigenius tusks from different localities. I examined whether and how the values of the Schreger angles, the qualitative pattern categories and the wavelengths change within the tusks - from the pulp cavity towards the tusk surface and from the proximal to distal portions; how they relate to each other and whether it is possible to use a piece of tusk (without known location) for species identification.

There are many localities with Mammuthus primigenius tusks within the area and proximity of the Czech Republic but there are only a few with tusk material suitable for microstructure analyses, where the ivory is not fragmentary and breakable. Those localities with the best preserved tusks were chosen for this study (see below).

\section{Material and methods}

To perform a microscopic study it is desirable to have compact, unweathered tusks, preferably tusks containing the pulp cavity, which is important for establishing the location of any cross section in the tusk. A gross sample of 198 specimens of tusks were collected and examined, with 71 of these yielding reliable measurements; only well-preserved tusk samples were used. The taxon, Mammuthus primigenius (Blumenbach, 1799) was determined at the site on the basis of dentition and skeletons found with the tusks.

The tusks are from five Upper Palaeolithic (Gravettian) Moravian localities in the Czech Republic ( 35-25 cal. ka BP): Předmostí (49 $28^{\prime} \mathrm{N}$; $\left.17^{\circ} 25^{\prime} \mathrm{E}\right)$; Pavlov (48 $52^{\circ} \mathrm{N}$; $\left.16^{\circ} 40^{\prime} \mathrm{E}\right)$; Dolní Věstonice (48 ${ }^{\circ} 53^{\prime} \mathrm{N}$; $16^{\circ} 38^{\circ} \mathrm{E}$ ); Milovice $\left(48^{\circ} 51^{\prime} \mathrm{N} ; 16^{\circ} 42^{\prime} \mathrm{E}\right)$; and Napajedla $\left(49^{\circ} 10^{\prime} \mathrm{N}\right.$; 17³1' E) (Oliva 1998; Svoboda et al. 2002); and one Würmian locality Viljevacki cret (Donji Miholjac) in

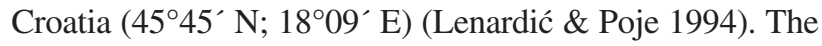
specimens are held in the collections of the Moravian $\mathrm{Mu}-$ seum (Brno, Czech Republic), the Institute of Archaeology of the Academy of Sciences (ASCR, Brno, Czech Republic) and the Institute for Quaternary Palaeontology and Geology, Croatian Academy for Sciences and Arts (Zagreb, Croatia).

In this study, I focused on a suite of features that create the Schreger pattern in the analysis of these tusks. These features consist of the Schreger angle, the wavelength of the corrugated sets of dentinal tubules, and the qualitative pattern, which is used in classifying the Schreger pattern. The features of the Schreger pattern were measured with respect to the distance from the tusk axis.

Two different methods were applied: thin sections, and etching and staining (after Debeljak 1996). This application of etching and staining of mammoth tusks is used here for the first time. In addition, cathode luminescence was used to try and distinguish the features of the Schreger pattern within the tusk dentine. However, this method was not found suitable for the analysis of tusks because the material showed no luminescence.

Thin sections. - Standard petrographic thin sections with $0.025 \mathrm{~mm}$ thickness were made from the tusks in transverse and longitudinal sections. The best way to obtain high-quality thin sections is to embed the tusk in a plaster coat and then cut the slices using a non water-based lubricant. Plaster is used as a supporting material to prevent the tusk from disintegrating during cutting. Non water-based lubricant is used in order to avoid water absorption by the tusk, which can cause swelling and consequent damage to the dry fossil material (Fox 2000).

Transverse sections were made perpendicular to the tusk growth surface in order to determine the Schreger angle values and the qualitative appearance of the pattern (' $\mathrm{C}$ ', ' $\mathrm{X}$ ' or ' $\mathrm{V}$ '; see Fig. 2A, C). The thin sections were studied with 

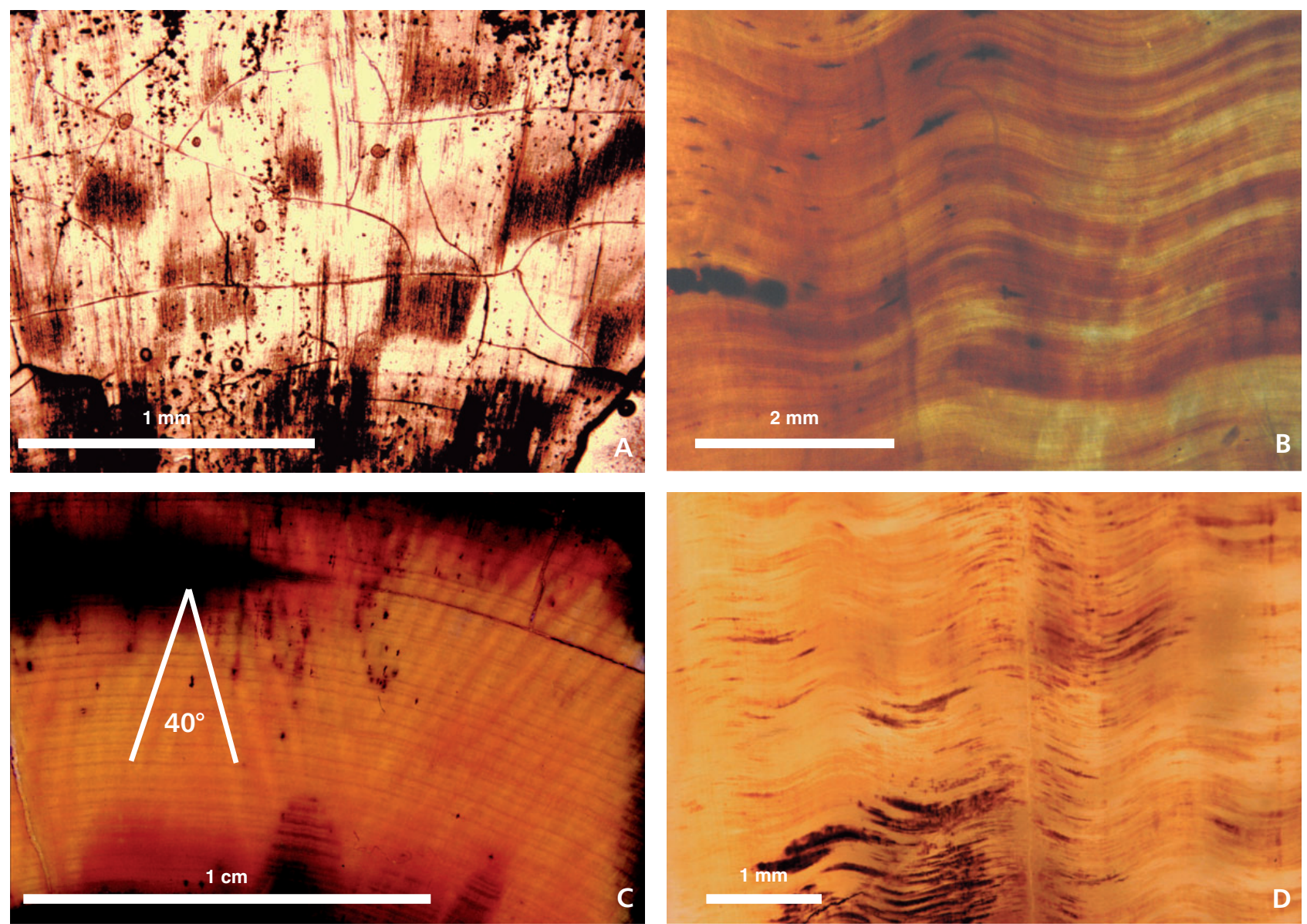

Figure 2. Thin sections of the tusks. • A - 'C' pattern. Transverse cross-section of Mammuthus primigenius tusk (Dolní Věstonice, Czech Republic). - B - undulating sets of dentinal tubules. Longitudinal cross-section of Mammuthus primigenius tusk (Viljevacki cret, Croatia). $\bullet \mathrm{C}-$ ' $\mathrm{V}$ ' pattern. Transverse cross-section of Mammuthus primigenius tusk (Milovice, Czech Republic). Transverse lines represents growth increments. $\bullet D-$ undulating sets of dentinal tubules. Longitudinal cross-section of Mammuthus primigenius tusk (Viljevacki cret, Croatia).

crossed polars, using eyepieces with $2.5 \times, 4 \times$ and $6.3 \times$ magnification. Longitudinal thin sections were made of parts running along the entire tusk length, parallel to the tusk axis. These sections were used to determine the wavelength of the corrugated sets of dentinal tubules (Fig. 2B, D). Plane polarized light and eyepieces with $2.5 \times, 4 \times, 6.3 \times, 10 \times$ and $20 \times$ magnification were used. From observations of thin sections made under the petrographic microscope, I conclude that the use of a $2.5 \times$ magnification eyepiece is most suitable as this view covers a larger area of the specimen than did higher magnification, and this enables more precise measurement of the Schreger angle values.

Etching and staining. - Ground sections have also been made from the tusks: transverse sections served for the Schreger angle measurements and determination of the qualitative appearance of the pattern (Fig. 3A); and longitudinal sections were also used to determine the wavelengths (Fig. 3B). When ground sections are to be made especially for etching and staining, it is not suitable to apply resin to the sample under vacuum pressure as this will drive resin into the pores and prevent the acid and stain from affecting the tusk surface.

The ground sections were etched with 10-20\% orthophosphoric acid $\left(\mathrm{H}_{3} \mathrm{PO}_{4}\right)$ for 5-10 minutes then rinsed with water. They were stained with approximately $0.5 \%$ aqueous solution of gentian violet (hexamethyl-p-rosaniline chloride or crystal violet). Gentian violet was applied to the root section with a paintbrush and rinsed with tap water after a few seconds. The intense violet colour disappears if the specimen is immersed in acid for a second time. This preparation is then studied under a binocular microscope. Using this technique produces sharp contrast zones between the studied characteristics.

For staining, the use of gentian violet is the cheapest and easiest of all methods and also suitable when preparation of thin sections is complicated by poor preservation of a tusk. Using gentian violet staining allowed us to study and measure the Schreger angles, wavelengths, and also to determine the qualitative patterns with the same accuracy achieved when using classical petrographic thin section 

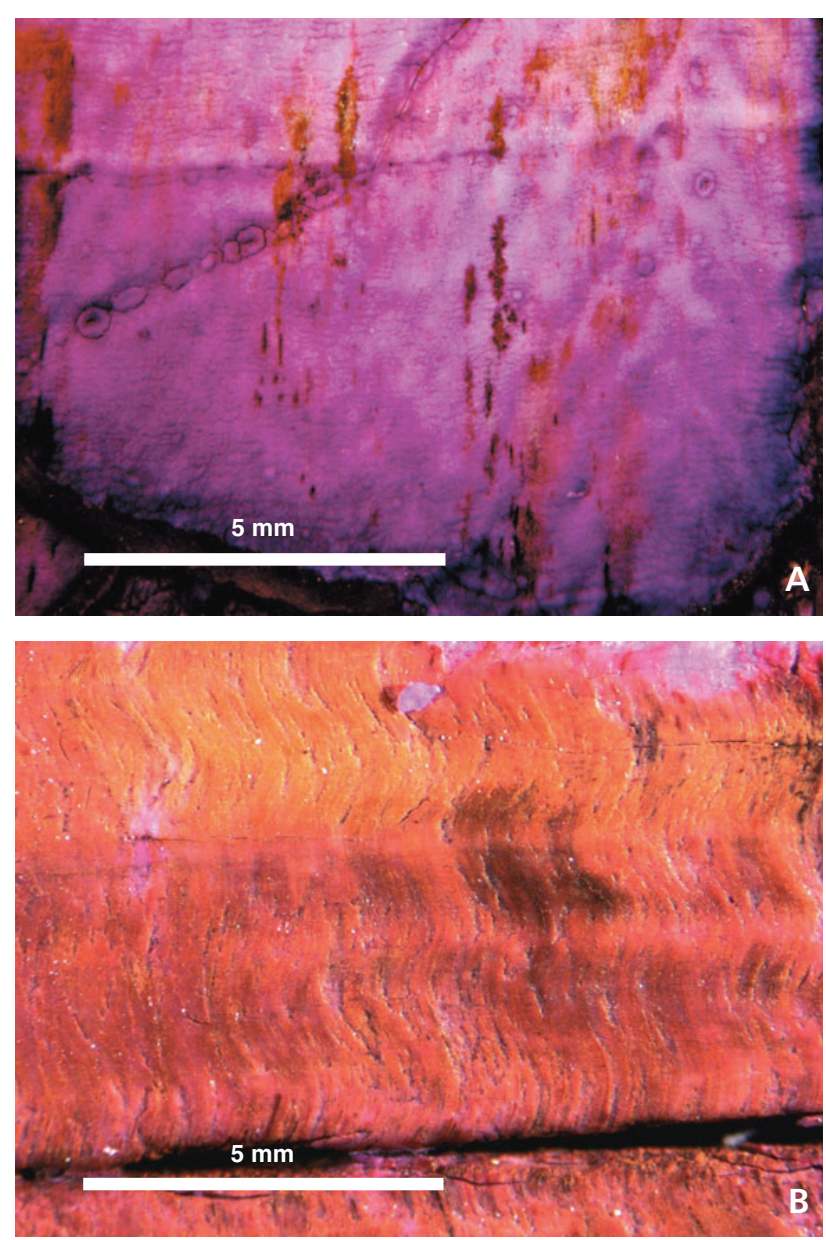

Figure 3. Etched and stained ground sections of $M$. primigenius tusks, Viljevacki cret, Croatia. $\bullet A-S c h r e g e r ~ ' V '$ pattern. Transverse ground section. $\bullet \mathrm{B}-$ undulating sets of dentinal tubules. Longitudinal ground section.

techniques. The Schreger angles were measured from microphotographs of transverse thin sections. Microphotographic images were taken using a petrographic microscope with crossed polars and a microscope-mounted CCD video camera plus, in several instances, a PC-connected digital camera. Each microphotograph was studied with 'Lucia' software for picture analysis, which allows measurement of the angles and wavelength. It is necessary to orient the tusk images and to indicate their orientation with respect to the surface. As many angles as possible were measured in order to determine variability in the Schreger angle values. Angles were also measured in the traditional way using a rotating microscope stage and eyepiece cross-hair, as did Trapani \& Fisher (2003).

When analysing the Schreger pattern from the stained ground sections the same method was applied to the thin sections using either a CCD camera or digital camera. Multiple measurements were made from most samples. Data for each individual consisted of measurements taken at various radial distances. Schreger angles were measured from the pulp cavity towards the tusk surface at $0.5 \mathrm{~cm}$ intervals. Each angle was measured three times and their average

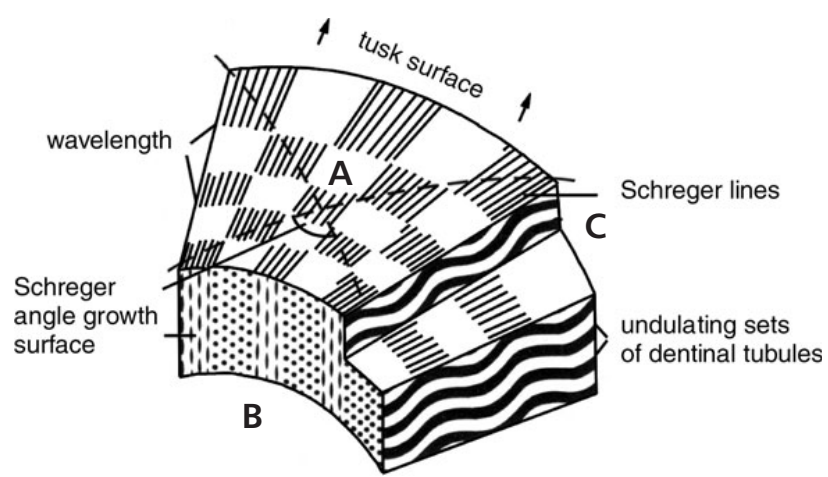

Figure 4. Transverse section of a tusk. (B) indicates the growth surface of the pulp cavity (inner part of tusk) showing six segmented columns of corrugated sets of dentine tubules. Parts of columns were removed in order to highlight the corrugation of tubulae in the individual columns (C). The phase of corrugation alternates from one column to another. This alternation produces the chessboard-like surface pattern (A). This chessboard-like pattern is visible with the naked eye even in small transverse sections of a tusk. It is a very distinct feature, which is sufficient evidence to identify genuine ivory (modified after Miles \& White 1960).

used. The total range of degrees recorded for repeated measurements of the same angle was usually $5^{\circ}$ or less.

Transverse thin sections were also used to determine the qualitative appearance of the pattern when observed with crossed polars. Three basic types of qualitative pattern exist: ' $C$ ', ' $V$ ' and ' $\mathrm{X}$ '; there are also several more secondary patterns, which originate at the transition from one pattern to another. The ' $C$ ' ('checkerboard') pattern consists of light and dark areas resembling a chessboard. These differently coloured areas represent macroscopic manifestations of systematic shifts in the corrugated paths of the dentine tubules. Diagonally adjacent dark and light areas come into contact only at their corners. The ' $\mathrm{V}$ ' pattern (resembling the letter $\mathrm{V}$ ) consists of continuous lines oblique to the incremental features; one direction (dextral or sinistral) is locally predominant. The ' $\mathrm{X}$ ' pattern (a criss-cross in an X-shape) consists of intersecting continuous lines, oblique to the incremental features and occurring both in the dextral and sinistral direction (Fig. 4; Trapani \& Fisher 2003).

Wavelength is the distance between two subsequent points in the dentine tubules located at an identical position. Wavelengths were measured several times in longitudinal sections on a petrographic microscope using parallel polars in order to determine minimum and maximum values.

\section{Results}

Based on the tusk microstructure analyses, the values of the Schreger angles, wavelength, and qualitative pattern appearance were found to be very closely related to each other although they change throughout the length of the tusk.

In my material I found that Schreger angles reach about $25-40^{\circ}$ near the pulp cavity. The angles increase toward 
the tusk surface and reach a maximum value of $\sim 125^{\circ}$ (Tables 1,2$)$. Schreger angle values also vary in relation to distance along the proximo-distal axis of the tusk. In the proximal (widest) part of the tusk there occur angle values from $25^{\circ}$ to $125^{\circ}$. Towards to the distal part of the tusk (the tip) these are reduced to low values. This means that Schreger angles depend on their location within the transverse tusk section, on the diameter of the transverse tusk section, and also on the location of the section sampled along the proximo-distal tusk axis.

Wavelengths reach maximum values at about $2,175 \mu \mathrm{m}$ at lower Schreger angles (near the pulp cavity). The length becomes shorter and measures about 1,100 $\mu \mathrm{m}$ towards the tusk surface and thereby towards higher values of Schreger angles (Table 1). The structure of the qualitative pattern depends mainly on its associated Schreger angles. ' $\mathrm{V}$ ' pattern occurs at low angle values in the vicinity of the pulp cavity and again at angle values between $25-90^{\circ}$. At maximum values (from approximately $70^{\circ}$ to $125^{\circ}$ ) near the tusk surface, ' $C$ ' pattern also occurs. Angle values between $50^{\circ}$ and $90^{\circ}$, found between the ' $\mathrm{V}$ ' and ' $\mathrm{C}$ ' patterns, correspond to the ' $\mathrm{X}$ ' pattern (Tables 1,3 ).

\section{Discussion}

\section{Schreger angle}

In this research I focused on the entire angle spectrum while recording the exact location of the angles within the transverse tusk section, including 'outer' (near the CDJ) and 'inner' angles (near the proximo-distal tusk axis). According to Espinoza \& Mann (1991), the 'outer' Schreger angles can reach approximately $125^{\circ}$, as is the case in this study and, as with their results, the Schreger angle averages at roughly $73^{\circ}$ and the spacing of the Schreger angles within the transverse tusk section is very similar (Fig. 5).

Palombo \& Villa (2001) stated that the variability ranges of Schreger angles measured near the CDJ for Mamuthus primigenius is from $65^{\circ}$ to $90^{\circ}$. Trapani \& Fisher (2003) measured 'outer' and 'inner' Schreger angles using the same methodology as described above. For mammoths, they found maximum Schreger angle values of approximately $70-100^{\circ}$ near the CDJ, and highest angle values occurring in transects taken more than $400 \mathrm{~mm}$ from the tusk tip and this study mostly confirms their observations. However, on the basis of the tusk measurements, I found some differences. With reference to Schreger angles, maximum values of $125^{\circ}$ were found for Mamuthus primigenius, and not only the $100^{\circ}$ as reported by Trapani \& Fisher (2003). This discrepancy between data of Trapani \& Fisher (2003), Palombo \& Villa (2001), and the present study might be because the angle of $125^{\circ}$ was recorded in only one case and, similarly, the angle of $115^{\circ}$ in only three cases. Likewise the minimal an-
Table 1. Mutual dependence of Schreger angles on the distance from the tusk surface and their qualitative pattern appearance.

\begin{tabular}{|c|c|c|c|c|}
\hline $\begin{array}{l}\text { Schreger } \\
\text { angle }\left[{ }^{\circ}\right]\end{array}$ & $\begin{array}{l}\text { Distance from tusk } \\
\text { surface }[\mathrm{cm}]\end{array}$ & $\begin{array}{l}\text { Wavelength } \\
{[\mu \mathrm{m}]}\end{array}$ & $\begin{array}{l}\text { Schreger } \\
\text { angle }\left[{ }^{\circ}\right]\end{array}$ & $\begin{array}{c}\text { Qualitative } \\
\text { pattern }\end{array}$ \\
\hline $115-90$ & near tusk surface & 1,100 & $25-90$ & V \\
\hline $110-50$ & 0.5 & & $50-90$ & $\mathrm{X}$ \\
\hline $125-40$ & 1 & & $70-125$ & $\mathrm{C}$ \\
\hline $120-30$ & 1.5 & $\begin{array}{l}\| \\
\text { shortening }\end{array}$ & & \\
\hline $110-25$ & 2 & & & \\
\hline $95-30$ & 2.5 & प & & \\
\hline $95-45$ & 3 & 2,175 & & \\
\hline $75-40$ & 3.5 & & & \\
\hline
\end{tabular}

Table 2. Matrix of Schreger angle measurements relative to the distance from the tusk surface to the pulp cavity. DFS - distance from tusk surface $[\mathrm{cm}]$.

\begin{tabular}{|c|c|c|c|c|c|c|c|c|c|c|}
\hline Angle $\left[{ }^{\circ}\right]$ & & & $\mathrm{mb}$ & of Sc & hre & angl & oc & rrence & & \\
\hline 125 & & & 1 & & & & & & & \\
\hline 120 & 1 & & & 1 & & & & & & \\
\hline 115 & & & 1 & 1 & & & & & & \\
\hline 110 & 1 & 1 & 2 & 1 & 1 & & & & & \\
\hline 105 & 2 & 4 & 2 & & & & & & & \\
\hline 100 & 1 & 7 & 2 & & & 1 & & & & \\
\hline 95 & 1 & 6 & 3 & 3 & & & & & & \\
\hline 90 & 2 & 6 & 5 & 1 & & 1 & 1 & & & \\
\hline 85 & & 3 & 4 & 3 & 1 & 2 & & & & \\
\hline 80 & & 4 & 5 & 3 & 5 & 2 & & & & \\
\hline 75 & & 3 & 3 & 4 & 1 & 2 & & 1 & & \\
\hline 70 & & 4 & 2 & 3 & 5 & 3 & 3 & & & \\
\hline 65 & & 2 & 1 & 3 & 4 & 3 & 3 & & & \\
\hline 60 & & 1 & 3 & 4 & 7 & 4 & 3 & & & \\
\hline 55 & & & 3 & 1 & 4 & 4 & 3 & & 1 & \\
\hline 50 & & 1 & 4 & 2 & 4 & 3 & & & & \\
\hline 45 & & & 1 & 1 & 2 & 3 & 3 & 1 & & \\
\hline 40 & & & 1 & 1 & 2 & 4 & 1 & 2 & & 1 \\
\hline 35 & & & & & 1 & & & & & \\
\hline 30 & & & & 1 & & 2 & & & & \\
\hline 25 & & & & & 1 & & & & & \\
\hline DFS & 0 & 0.5 & 1 & 1.5 & 2 & 2.5 & 3 & 3.5 & 4 & 5 \\
\hline
\end{tabular}

gles $25^{\circ}, 30^{\circ}$ and $35^{\circ}$ were recorded only minimally. The largest number of measured angles occurs between $40^{\circ}$ to $110^{\circ}$. Maximum angle values occur near the CDJ, around 0-2 cm from the tusk surface (Table 2).

Measurements here were carried out without recording a more accurate positioning of the sample along the proximo-distal tusk axis. This was necessary in the majority of cases because my tusk samples generally lacked the tusk tip, from which it would be possible to take such measurements. The material came from Palaeolithic sites and therefore their completeness and length were probably influenced by human impact (Fig. 6). For this study, tusk lengths varied from 13 to $59 \mathrm{~cm}$ and tusk diameter varied from $5.5 \mathrm{~cm}$ to $11.5 \mathrm{~cm}$. I think that the greater 
Table 3. Matrix of qualitative pattern dependence on Schreger angles. $\mathrm{N}=$ number of qualitative pattern occurrences.

\begin{tabular}{|c|c|c|c|c|}
\hline \multirow[t]{2}{*}{ Angle $\left[{ }^{\circ}\right]$} & \multicolumn{4}{|c|}{ Qualitative pattern } \\
\hline & $\mathrm{C}$ & $\mathrm{X}$ & $\mathrm{V}$ & $\mathrm{N}$ \\
\hline 125 & 1 & & & 1 \\
\hline 120 & 2 & & & 2 \\
\hline 115 & 2 & & & 2 \\
\hline 110 & 6 & & & 6 \\
\hline 105 & 9 & & & 9 \\
\hline 100 & 11 & & & 11 \\
\hline 95 & 10 & 3 & & 13 \\
\hline 90 & 12 & 3 & 1 & 16 \\
\hline 85 & 5 & 5 & 2 & 12 \\
\hline 80 & 8 & 8 & 3 & 19 \\
\hline 75 & & 7 & 7 & 14 \\
\hline 70 & 1 & 7 & 12 & 20 \\
\hline 65 & & 6 & 10 & 16 \\
\hline 60 & & 3 & 19 & 22 \\
\hline 55 & & & 15 & 15 \\
\hline 50 & & 1 & 13 & 14 \\
\hline 45 & & & 11 & 11 \\
\hline 40 & & & 13 & 12 \\
\hline 35 & & & 1 & 1 \\
\hline 30 & & & 3 & 3 \\
\hline \multirow[t]{2}{*}{25} & & & 1 & 1 \\
\hline & $\leftarrow$ tusk surface & & pulp cavity $\rightarrow$ & \\
\hline $\mathrm{N}$ & 67 & 43 & 111 & 221 \\
\hline
\end{tabular}

Schreger angle range in my material occurs because the Schreger angles were measured on samples taken from various unknown positions along the proximo-distal tusk axis.

It follows that Schreger angles depend on both the location of the sample from within the transverse tusk section, and also on their location along the proximo-distal tusk axis. Schreger angles become smaller towards the distal end (tip) of the tusk.

\section{Qualitative pattern type}

In the study of Trapani \& Fisher (2003), mammoths showed predominantly ' $\mathrm{X}$ ', and rarely ' $\mathrm{C}$ ' patterns, near the $\mathrm{CDJ}$; ' $\mathrm{V}$ ' patterns are more common at low angle values near the tusk axis. Mammoth wavelengths are relatively long (usually greater than $1 \mathrm{~mm}$ ) and become very long at low Schreger angles near the tusk axis, often associated with a transition from ' $\mathrm{X}$ ' to ' $\mathrm{V}$ ' patterns. In the present samples the ' $\mathrm{C}$ ' pattern was not rare, being present in $65 \%$ of the studied tusks.

The qualitative pattern appearance depends on the Schreger angle value. A ' $V$ ' pattern occurs in the tusk samples at angles from $25^{\circ}$ to $90^{\circ}$; an ' $\mathrm{X}$ ' pattern at angles from $50^{\circ}$ to $90^{\circ}$; and a ' $\mathrm{C}$ ' pattern from $70^{\circ}$ to $125^{\circ}$, with some overlap existing within the studied material (Table 3 ). The

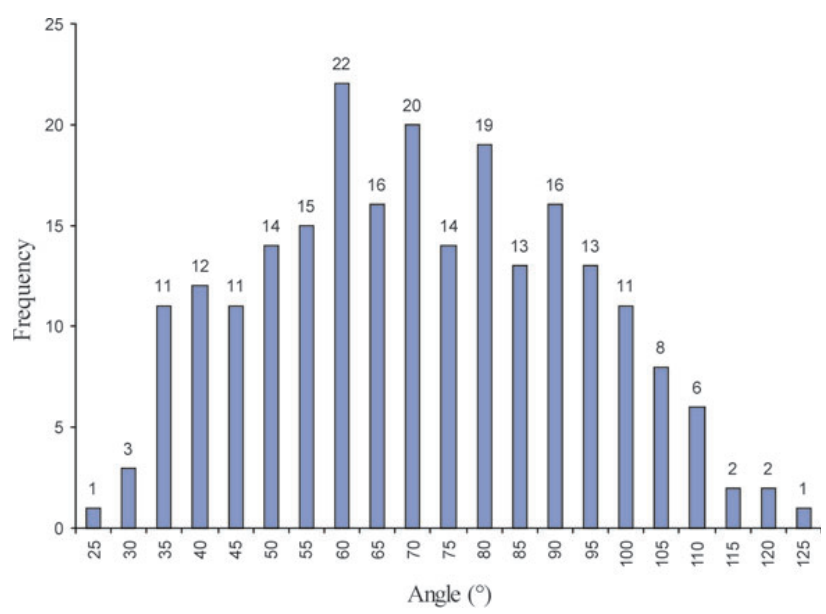

Figure 5. Plot of mean Schreger angles from Mamuthus primigenius tusks in this study $(\mathrm{N}=71)$.

qualitative pattern types also change relative to their proximo-distal distance from the tip, the evidence suggesting that a ' $\mathrm{C}$ ' pattern recorded at a particular distance from the tusk surface (in transverse section) changes towards the distal direction (towards the tusk tip) from ' $\mathrm{C}$ ', through ' $\mathrm{X}$ ', towards a ' $\mathrm{V}$ ' pattern.

\section{Wavelength}

Trapani \& Fisher (2003) stated that mammoths typically have wavelengths of $1 \mathrm{~mm}$ or greater and that wavelength greatly increases at low Schreger angle and near the tusk axis. My research supports their findings as I find that near the pulp cavity (at lower Schreger angles) the wavelength reaches the value of about $2,175 \mu \mathrm{m}$ and towards the tusk surface (higher values of Schreger angles), the length becomes shorter, measuring about $1,100 \mu \mathrm{m}$. Also, the wavelength becomes longer from the proximal towards the distal part of the tusk.

These results suggest that it may be possible to identify the proximal-distal location of a partial tusk fragment and, if so, such a study of tusk fragments might also be usefully applied to the analyses of Palaeolithic artefacts made from mammoth's tusks. Based on the findings presented here, the location of tusk pieces or artefacts within the transverse section of Mamuthus primigenius tusks can be determined on the basis of the Schreger angles, the qualitative patterns present, and wavelength distances.

When attempting to determine the proboscidean species on the basis of tusk fragments that do not comprise the whole tusk section or, at best, offer a sample without known location within the tusk, one needs to be very careful because some overlap in the measured angle values exists between taxa. Care must be taken if one hopes to avoid making a false determination. 


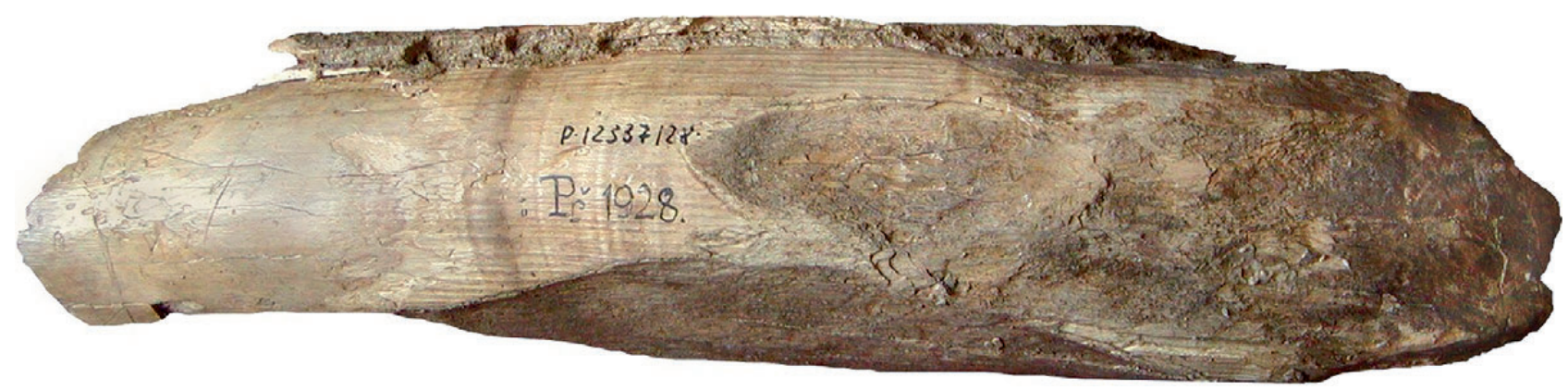

Figure 6. Worked Mamuthus primigenius tusk from Předmostí (P 12337/28, Př 1928), Czech Republic.

\section{Conclusions}

Based on this research and other results, it seems clear that the observations apply generally to all Mammuthus primigenius tusks, regardless of their geological or geographic area. My results thus demonstrate that the positioning of Schreger angles, the presence and position of qualitative patterns, and the wavelengths (relative to the distance from the pulp cavity towards the tusk surface) are similar in all specimens regardless of site or geological age. The smallest angles, ' $\mathrm{V}$ ' pattern, and longest wavelengths occur near the pulp cavity. Angles become larger, patterns change from ' $\mathrm{V}$ ', through ' $\mathrm{X}$ ', to ' $\mathrm{C}$ ', and wavelengths become shorter towards the tusk surface.

Microscopic study of 71 Mamuthus primigenius tusks enabled us to investigate features of the Schreger pattern. The average Schreger angle from these samples was $70^{\circ}$ $\left(\right.$ standard deviation $\left.=21.17^{\circ}\right)$, with a range from $25^{\circ}$ to $125^{\circ}$. Maximum wavelength values of about 2,175 $\mu \mathrm{m}$ were found at low Schreger angles near the pulp cavity. Minimum wavelength values of about $1,100 \mu \mathrm{m}$ were found near the CDJ. A ' $V$ ' pattern occurs at angle values between $25^{\circ}$ and $90^{\circ}$; a 'C' pattern occurs from approximately $70^{\circ}$ to $125^{\circ}$; and an ' $\mathrm{X}$ ' pattern between $50^{\circ}$ and $90^{\circ}$.

In this study, I was not able to consider whether Schreger angle is dependent on gender, because it was not possible to allocate the tusks in the sample to male or female. However, observations on tusks of different individuals (both young and old) show that the degree of Schreger angles does depend on age: younger individuals have lower angles than do older (in agreement with Palombo \& Villa 2001).

By examining specimens coming from different geographic areas (as did Palombo \& Villa 2001) and different Palaeolithic ages, it seems that neither environmental factors nor geological age influence the Schreger angles, wavelength or qualitative pattern type. Some differences might be apparent because Schreger angles do change within the transverse section of a tusk (from the pulp cavity towards the tusk surface), and also proximo-distally within the longitudinal tusk section. Careful attention to Schreger angles, qualitative patterns, and wavelengths within a tusk section may enable us to identify not only the species of mammoth ivory from whole tusks, but also the species for artefacts made from fragments of tusk ivory.

The ability to identify tusks and their fragments as well as from microscopic analyses of tusks of different proboscidean taxa can be extremely useful from various viewpoints. Further research in this field is desirable owing to the potential for identification of proboscidean species without the presence of diagnostic molars, skull or postcranial skeleton. This approach is useful especially when fossil remains of a single animal are not preserved together and their taphonomic position is allochthonous. Tusk microstructure analyses may therefore provide the necessary information to determine the origin of artefacts made of ivory.

\section{Acknowledgements}

The author is grateful to the Moravian Museum (Brno, Czech Republic), to M. Nývltová Fišáková (Institute of Archaelogy of the ASCR, Czech Republic), and to J.M. Lenardić (Croatian Academy for Sciences and Arts, Zagreb, Croatia), for supplying the tusk material; to B.R. Barton for extensive editing of an earlier draft of this manuscript; to J. Saunders and J. Trapani for discussions and literature; and to D. Nývlt for critical reading of the manuscript. This research was supported by the FRVŠ grant of the Ministry of Education, Youth and Sports of ČR, No. 5109.

\section{References}

Abramova, Z.A., GrigorievA, G.V. \& ZAITSEV, G.I. 2001. The age of Upper Paleolithic sites in the Middle Dnieper River Basin of Eastern Europe. Radiocarbon 43, 1077-1084.

BLUMENBACH, J.F. 1799. D.J.F. Blumenbach's Handbuch der Naturgeschichte. $6^{\text {th }}$ edition. 708 pp. Dieterich, Göttingen.

Brody, R.H., EdWARdS, H.G.M. \& POLlard, A.M. 2001. Chemometric methods applied to the differentiation of Fouriertransform Raman spectra of ivories. Analytica Chimica Acta 427, 223-232. DOI 10.1016/S0003-2670(00)01206-X

DEBELJAK, I. 1996. A simple preparation technique of cave bear teeth for age determination by cementum increments. Revue de Paléobiologie, Genève 15(1), 105-108.

EDWARDS, H.G.M., FARWELl, D.W., HOLDER, J.M. \& LAWSON, 
E.E. 1997. Fourier-transform Raman spectroscopy of ivory: III. Identification of mammalian specimens. Spectrochimica Acta Part A 53, 2403-2409.

DOI $10.1016 / \mathrm{S} 1386-1425(97) 00180-7$

ESPINOZA, E.O. \& MANN, M.J. 1991. Identification guide for ivory and ivory substitutes. $2^{\text {nd }}$ edition. 38 pp. World Wildlife Fund and Conservation Foundation, Baltimore.

ESPINOZA, E.O. \& MANN, M.J. 1993. The history and significance of the Schreger pattern in proboscidean ivory characterization. Journal of the American Institute for Conservation 32, 241-248. DOI $10.2307 / 3179547$

FISHER, D.C. 2001. Season of death, growth rates, and life history of North American mammoths, 121-135. In WEST, D. (ed.) Proceedings of the International Conference on Mammoth Site Studies. Publications on Anthropology 22. University of Kansas, Lawrence.

FISHER, D.C., TRAPANI, J., SHOSHANI, J. \& WOODFORD, M. 1998. The Schreger pattern in mastodon and mammoth tusk dentin. Current Research in the Pleistocene 15, 105-107.

FOX, D.L. 2000. Growth increments in Gomphotherium tusk and implications for late Miocene climate change in North America. Palaeogeography, Palaeoclimatology, Palaeoecology 156, 327-348. DOI 10.1016/S0031-0182(99)00148-0

Gelvin-ReYMiLleR, C., Reuther, J.D., POTTER, B.A. \& BOWERS, P.M. 2006. Technical aspects of a worked proboscidean tusk from Inmachuk River, Seward Peninsula, Alaska. Journal of Archaeological Science 33, 1088-1094.

DO] 10.1016/j.jas.2005.11.015

HALBERG, F. 1969. Chronobiology. Annual Review of Physiology 31, 675-725. DOI 10.1146/annurev.ph.31.030169.003331

Halberg, F., Engeli, M., Hamburger, C. \& Hillman, D. 1965. Spectral resolution of low-frequency, small-amplitude rhythms in excreted 17-ketosteroids; probable androgen-induced circaseptan desynchronization. Acta Endocrinologica 50(103), 1-54.

HERRERA, J.C. 1999. Determining the species source of prehistoric ivory. Aucilla River Times 10(1), 17.

Kautenburger, R., WANnemacher, J. \& Müller, R. 2004. Multi element analysis by X-ray fluorescence: a powerful tool of ivory identification from various origins. Journal of $R a$ dioanalytical and Nuclear Chemistry 260, 399-404.

DOI 10.1023/B:JRNC.0000027115.68661.98

KHLOPATCHEV, G.A. 2001. Mammoth tusk processing using the knapping technique in the Upper Paleolithic of the Central Russian Plain, 444-447. In CAVARRETTA, G., GioiA, P., Mussi, V. \& PALOMBO, M.R. (eds) The World of Elephants. Proceedings of the $1^{\text {st }}$ International Congress. Consiglio Nazionale delle Ricerche, Rome, Italy.

LAMBERT, W.D. 2005. The microstructure of proboscidean ivory and its application to the subordinal identification of isolated ivory specimens. Bulletin of the Florida Museum of Natural History 45, 521-530.

LENARDIĆ, J.M. \& POJE, M. 1994. Elephant remains and attendant malacological fauna from some localities in Slavonia, Croatia, 41. Neogene and Quaternary Mammals of the Palearctic. Conference in honour of Prof. Kazimierz Kowalski. Krakow, Poland, 17.-21.5. 1994.

MiLes, A.E.W. \& White, J.W. 1960. Ivory. Proceedings of the Royal Society of Medicine 53, 775-780.
Oliva, M. 1998. Gravettien východní Moravy. Acta Musei Moraviae $83,3-65$.

OWEN, R. 1840-1845. Odontography. 655 pp. Hippolyte Bailliere, London.

PALOMBO, M.R. \& VILLA, P. 2001. Schreger lines as support in the Elephantinae identification, 656-660. In CAVARRETTA, G., Gioia, P., Mussi, V. \& PALOMBO, M.R. (eds) The World of Elephants. Proceedings of the $1^{\text {st }}$ International Congress. Consiglio Nazionale delle Ricerche, Rome, Italy.

Prozesky, V.M., RAUbenheIMER, E.J., VAN HEERDEN, W.F.P., Grotepass, W.P., Przybylowicz, W.J., Pineda, C.A. \& SWART, R. 1995. Trace element concentration and distribution in ivory. Nuclear Instruments and Methods in Physics Research B 104, 638-644. DOI 10.1016/0168-583X(95)00471-8

RAUBENHEIMER, E.J., BOSMAN, M.C., VORSTER, R. \& NOFFKE, C.E. 1998. Histogenesis of the chequered pattern of ivory of the African elephant (Loxodonta africana). Archives of Oral Biology 43, 969-977. DOI 10.1016./S0003-9969(98)00077-6

SAUNDERS, J.J. 1979. A close look at ivory. The Living Museum, Springfield 41(4), 56-59.

SCHEER, A. 2001. The utilisation of mammoth remains as raw material and its importance for the Gravettian people of the German Danube, 455-459. In CAVARRETTA, G., GiOIA, P., MusSI, V. \& PALOMBO, M.R. (eds) The World of Elephants. Proceedings of the $1^{\text {st }}$ International Congress. Consiglio Nazionale delle Ricerche, Rome, Italy.

SCHREGER, B.N.G. 1800. Beitrag zur Geschichte der Zähne. Beitrage für die Ergliederungkunst 1, 1-7.

Shimoyama, M., MAEdA, H., SATO, H., NinOMIYA, T. \& OZAKI, Y. 1997. Nondestructive discrimination of biological materials by near-infrared Fourier transform Raman spectroscopy and chemometrics: discrimination among hard and soft ivories of African elephants and mammoth tusks and prediction of specific gravity of the ivories. Applied Spectroscopy 51, 1154-1158.

DO1 $10.1366 / 0003702971941674$

SHIMOYAMA, M., NAKANISHI, T., HAMANAGA, Y., NiNOMIYA, T. \& OZAKI, Y. 1998. Non-destructive discrimination between elephant ivory products and mammoth tusk products by glancing incidence X-ray fluorescence spectroscopy. Journal of Trace and Microprobe Techniques 16, 175-182.

SvobodA, J., HAVLÍČEK, P., LOŽEK, V., MACOUN, J., MusiL, R., PŘICHYSTAL, A., SVOBODOVÁ, H. \& VLČEK, E. 2002. Paleolit Moravy a Slezska. Dolnověstonické studie 8.303 pp. Archeologický ústav AV ČR, Brno.

ŠKRDLA, P. 2005. The Upper Paleolithic on the Middle Course of the Morava River. Dolnověstonické studie 13.229 pp. Archeologický ústav AV ČR, Brno.

TOBIEN, H. 1978. On the Evolution of mastodonts (Proboscidea, Mammalia). Part 2: The bunodont tetralophodont groups. Geologisches Jahrbuch, Hessen 106, 159-208.

TRAPANI, J. \& FISHER, D.C. 2003. Discriminating proboscidean taxa using features of the Schreger pattern in tusk dentin. Journal of Archaeological Science 30, 429-438.

DOI 10.1016/jasc.2002.0852

VASILEV, S.A. 2001. Man and mammoth in Pleistocene Siberia, 363-366. In Cavarretta, G., Gioia, P., Mussi, V. \& PALOMBo, M.R. (eds) The World of Elephants. Proceedings of the $1^{s t}$ International Congress. Consiglio Nazionale delle Ricerche, Rome, Italy. 